\title{
PRIORITIZATION OF PLAYABILITY HEURISTIC EVALUATION FOR EDUCATIONAL COMPUTER GAMES (PHEG) TECHNIQUE USING ANALYTIC HIERARCHY PROCESS
}

\author{
Hasiah Mohamed* \\ Faculty of Computer and Mathematical Sciences, \\ Universiti Teknologi MARA, \\ Sura Hujung, 23000 Dungun, Terengganu, MALAYSIA \\ E-mail: hasia980@tganu.uitm.edu.my \\ Azizah Jaafar \\ Institute of Visual Informatics, \\ Universiti Kebangsaan Malaysia, \\ 43600 Bangi, Selangor, MALAYSIA \\ E-mail: aj@ftsm.ukm.my
}

\begin{abstract}
A holistic technique known as Playability Heuristic Evaluation for Educational Computer Game (PHEG) was developed. Heuristic based concept was used throughout the development of PHEG. It includes five heuristics; interface, educational elements, content, playability and multimedia. This study explores the importance of these five heuristics using Analytic Hierarchy Process (AHP) method. In the study, 15 selected experts from various fields performed AHP. The study found that the most important heuristic focused in evaluating usability of ECG is the interface, $40.8 \%$. The second important heuristic is educational element, $25.44 \%$, followed by content, $14.57 \%$, playability, $11.2 \%$ and multimedia, $8 \%$. Based on the result, the usability problems of the ECG will be identified in the future discussions using the same method.
\end{abstract}

Keywords: heuristics based, PHEG, usability of educational computer games, evaluation, educational computer games

\section{Introduction}

Usability is one of the main and core concepts that emerged from Human Computer (HCI) Interaction field. Various definition of usability is available and amongst them are: "the capability to be used by humans easily and effectively" (Barendregt, Bekker, Bouwhuis, \& Baauw, 2006), "quality in use" (Dempsey, Lucassen, Haynes, \& Casey, 1997) and "the effectiveness, efficiency, and satisfaction with which specified users can achieve goals, in particular environments" (Ke, 2008). International Organization for Standardization (ISO) defined usability as "the extent to which the product can be used by specified users to achieve specified goals with effectiveness, efficiency, and satisfaction in a specified context of use" $(\mathrm{Ke}, 2008)$ and it is one of the widely used definitions by researchers. The evolution of usability has been discussed and researched by various scholars and later, they developed various techniques and criteria to conduct usability studies (Malone, 1980; Papastergiou, 2009; Taylor, Pountney, \& Baskett, 2008). One of the popular techniques that being developed by (J. Nielsen, 1994) is Heuristics Evaluation (HE).

$\mathrm{HE}$ is an inspection evaluation technique that normally being used by an expert to find usability problem in any product or system (J. Nielsen, 1994). HE commonly used for formative evaluation where the product or system is still in development process. HE involves a small number of evaluators (expert in specific field) who have been assigned to inspect a system according to heuristics or guidelines that relevant and focused on the interface of the system. HE can be used both in design and evaluation phases of development and can even be applied to paper-based designs before the first

\footnotetext{
${ }^{*}$ Corresponding author
} 
working prototype is created (J. Nielsen, 1994). HCI studies showed that using five evaluators may be enough to find most usability problems, adding more would reduce the benefit to the cost ratio, and suggested that three may suffice (J. Nielsen, 1994). The HE technique has been emerged from evaluation of software (system and products) to one of the most popular applications nowadays that is games (Desurvire, 2004).

In HE, a list of heuristics attributes covers common criteria for any system and focuses on user interface and interaction elements. These elements cover all perspective of system in general, but in terms of educational computer game (ECG), no specific heuristics cater all elements neededto evaluate ECG such as educational design and contents. Therefore, having a comprehensive set of heuristics that focuses on ECG is required. Argument to the requirement is usability in ECG should cover various elements of education if they are to be applied in teaching and learning formally. Elements of education such as content and educational design should be taken into consideration in evaluation. Specific evaluation technique that accommodate all the important criteria of educational computer games has been proposed by Mohamed and Jaafar (Mohamed \& Jaafar, 2010) known as Heuristic Evaluation for Educational Computer Game (PHEG). PHEG accommodate of five heuristics in evaluating usability of educational computer games (Usa-ECG); interface, educational element, content, playability and multimedia. PHEG is developed based on experts' opinion and later it has been verified by prominent experts.

Development of PHEG is further extended with the integration of Multi-Criteria Decision Model (MCMD) in the evaluation system, particularly Analytic Hierarchy Process (AHP). The Analytical Hierarchy Process (Saaty, 1990) is a decision approach designed to aid in the solution of complex multiple criteria problems in a number of application domains. AHP is widely used since its introduction in 1972(Saaty, 1990). Example of application in information technology related area that use Analytic Hierarchy Process are software evaluation, evaluation of website performance and software design. This paper describes how AHP can be used to calculate the weights for a set of criteria (heuristic) and indicators (sub-heuristic) respectively. Through this multi-criteria decision making process, the importance of each heuristics can be determined.

\section{Background}

Nielsen and Molich (1994) introduced a method to be used with their set of usability guidelines. Heuristic evaluation (HE) is a usability engineering method "for finding usability problem in user interface design by having a small set of evaluators examine the interface and judge its compliance with recognized usability principles (the "heuristics"). The "heuristics' are design guidelines or principles for good interaction design and the aim are to find the problematic aspects of the design in order to improve it. This method uses evaluators to find usability problems or violations that may have a deleterious effect on the user to interact with the system. Typically, these evaluators are experts in usability principles, the domain of interest, or both (so-called "double" experts). Nielsen and Molich (Jacob Nielsen \& Molich, 1994) described the HE methodology as "cheap", "intuitive", "requires no advance planning," and finally, "can be used in development process." Often it is used in conjunction with other usability methodologies to evaluate user interfaces (Federoff, 2002).

In an evaluation process, finding flaws earlier rather than later able to reduce usability errors, which may be more costly to rectify once the application is completed. This is when the HE is relevant because of its capabilities in assisting evaluators to identify usability problem in the early stage of development process. Indeed, $\mathrm{HE}$ also can be used in the spiral or iterative development environment commonly found in the design industry system. 


\subsection{Heuristic based evaluation criteria in computer game}

Heuristics evaluation shown a huge potential to be a valuable evaluation tool for computer game since the development of HE related to computer game were recorded increasingly started on 1982 until now. Development of evaluation and design guideline included of guidelines to design enjoyable interfaces, a set of game design principles, three areas of computer games; game interface, game mechanics and game playability, the developed heuristic known as Heuristics for Evaluating Playability (HEP). Other than HEP, several more heuristic based evaluation for computer game are Playability heuristics for mobile games, key factors of heuristics evaluation for game design, key factors of heuristics evaluation for game design and categorized game heuristics on four areas; game interface, game play, game narrative and game mechanic, heuristics evaluation for video game design, usability inspections for games (Malone, 1980; Clanton, 1998; Desurvire, 2004; Federoff, 2002; Hannu \& Elina, 2006; Pinelle \& Wong, 2008; Song \& Lee, 2008).

Other than, specific heuristic based evaluation for computer games, heuristic for educational element were developed by scholars (Quinn, 1996; Albion, 1999; Benson, 2002; Ssemugabi \& Villiers, 2007; Nokelainen, 2006; Shee \& Wang, 2008). Quinn (1996) developed eight heuristics based upon educational theories, Albion (1999) compiled and developed the pedagogical heuristic and content heuristics, Reeves (2002) identified 7 instructional design heuristic to evaluate e-learning program, Ssemugabi And Villiers (2007) identified 8 sub-heuristic that relate to instructional design, Nokelainen (2006) studied about pedagogical usability criteria for evaluating the digital learning material and Daniel and Wang (2008) identified four dimensions in evaluating web-based e-learning system.

\subsection{Analytic Hierarchy Process (AHP)}

The Analytic Hierarchy Process (AHP) was developed by Saaty (Saaty, 1990) and this method is use to formalizing decision making where there are a limited number of choices but each has a number of attributes and it is difficult to formalize some of those attributes. These are characterized by a choice of criteria, which might be meaningful for an evaluation. These criteria are classified according to their relevance. AHP can be used for analyzing problematic situations and for preparing assessments and decisions. It was described in detail in the literature (e.g. (Saaty, 1990, 1994)). The AHP has been used in a large number of applications to provide some structure on a decision making process.

The AHP is based on the pair-wise comparison of any items contained in a set of indicators. For the comparisons a scale of nine valueswas suggested (Saaty, 1990). These and their related verbal definitions are listed in Table 1. If an expert prefers an indicator with extreme importance compared to another one the value 9 should be used. In the case the expert does not favor one of the two considered indicators values, 1 is to be used which means equal importance. All intermediate values represent various degrees of importance. The AHP approach is composed by the following steps:

1. Define the problem and determine its goal.

2. Structure the hierarchy from the top (the objectives from a decision-maker's viewpoint) through the intermediate levels (criteria on which subsequent levels depend) to the lowest level which usually contains the list of alternatives.

3. Construct a set of pair-wise comparison matrices (size $\mathrm{NxN}$ ) for each of the lower levels with one matrix for each element in the level immediately above by using the relative scale measurement shown in Table 2. The pair-wise comparisons are done interface terms of which element dominates the other.

4. There are $n(n-1)$ judgments required to develop the set of matrices in step 3. Reciprocals are automatically assigned in each pair-wise comparison.

5. Hierarchical synthesis is now used to weight the eigenvectors by the weights of the criteria and the sum is taken over all weighted eigenvector entries corresponding to those in the next lower level of the hierarchy. 
6. Having made all the pair-wise comparisons, the consistency is determined by using the eigenvalue, $\lambda \max$, to calculate the consistency index, CI as follows: $\mathrm{CI}=(\lambda \max -n) /(n-1)$ where $n$ is the matrix size. Judgment consistency can be checked by taking the consistency ratio (CR) of CI with the appropriate value in Table 1 . The CR is acceptable, if it does not exceed 0.10 . If it is more, the judgment matrix is inconsistent. To obtain a consistent matrix, judgments should be reviewed and improved.

7. Steps 3-6 are performed for all levels in the hierarchy.

Table 1. Scale and definitions of pair-wise comparisons (Saaty 1980).

\begin{tabular}{|c|l|}
\hline Weight & Interpretation \\
\hline 1 & Equally preferred/important \\
\hline 2 & Equally to moderately preferred /important \\
\hline 3 & Moderatly preferred /important \\
\hline 4 & Moderatly to strongly preferred /important \\
\hline 5 & Strongly preferred /important \\
\hline 6 & Strongly preferred to very strongly preffered /important \\
\hline 7 & Very strongly preferred/important \\
\hline 8 & Very to extremely strongly preffered/important \\
\hline 9 & Extremely preferred/important \\
\hline
\end{tabular}

Table 2. Random index for pairwise comparison matrices (RI)

\begin{tabular}{|l|l|l|l|l|l|l|l|l|l|l|}
\hline Matrix size (n) & 1 & 2 & 3 & 4 & 5 & 6 & 7 & 8 & 9 & 10 \\
\hline Random Consistency Index (RI) & 0.00 & 0.00 & 0.58 & 0.90 & 1.12 & 1.24 & 1.32 & 1.41 & 1.45 & 1.49 \\
\hline
\end{tabular}

\section{Methodology}

\subsection{Conceptual Design}

Development of PHEG consists of involvement of expert to review, suggest andedit the initial list of PHEG1 provided by researcher. Once the process of expert review done, researcher compile and restructure the list, PHEG2. In the final phase of developing PHEG, prominent experts were asked to verify the edited version of PHEG2, this produce the final version of the heuristic based evaluation technique, known as PHEG. Later, different expert were asked to perform AHP to prioritize the heuristic and sub-heuristic list in PHEG.

During the process of developing PHEG, development of an evaluation system known as AHP_HeGES took part. Overall process flow and 3 main modules were identified. The modules are PHEG module, AHP module and PAEG module (for real user). All of the data gather from the development of PHEG and evaluation process are stored in the database. Administrator has the authority to access the database and the system is able to produce report based on specific requirement. Figure1 shows the conceptual design of the system. There are two types of evaluators involve in the evaluation process; expert evaluator and real users. 


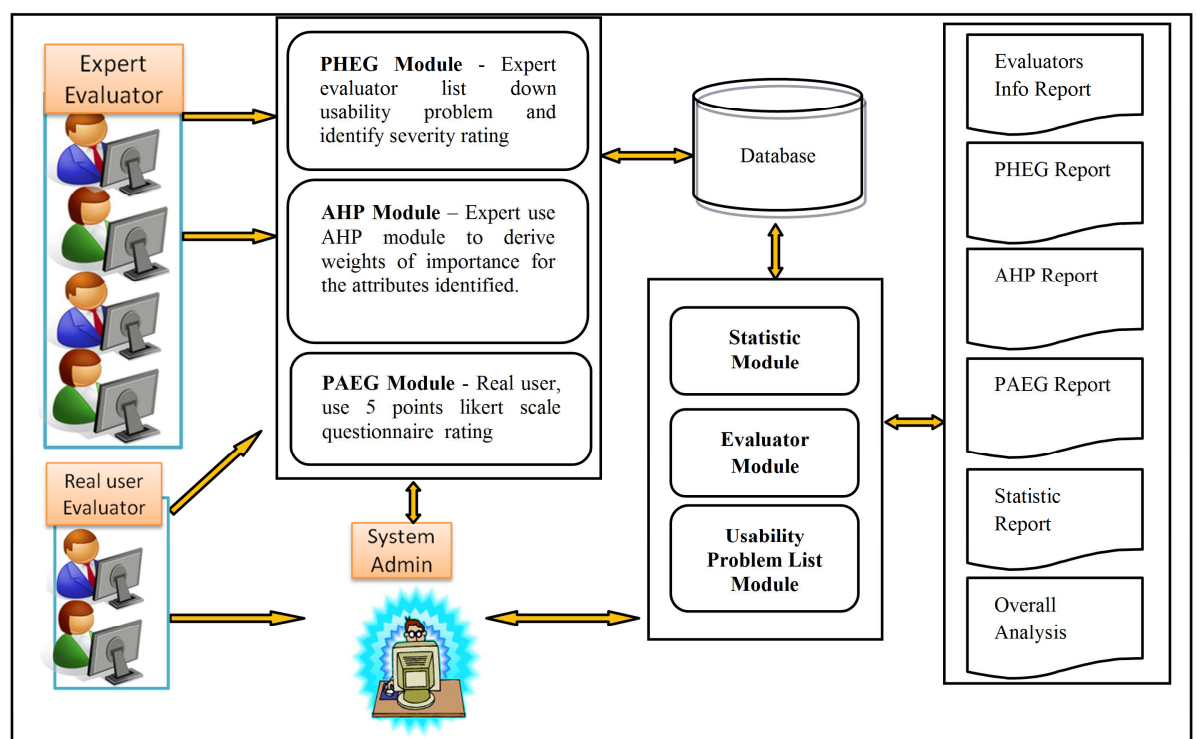

Figure 1. Conceptual design of the AHP_HeGES evaluation system

\subsection{Research Method}

Development of the evaluation technique, PHEG produces 5 heuristic with 37 sub-heuristics (Interface (10), Educational element (6), Content (6), Playability (7) and Multimedia (8)). The first module is for the expert evaluator to perform evaluation of ECG and identified usability problem of ECG. The Second module is regarding the integration of Analytic Hierarchy Process method in the system (AHP_HeGES). This method is important in order to view experts' opinion regarding the importance of heuristics andsub-heuristics. Figure 2 shows the hierarchy structure of usability for educational computer games.

The integration of Analytic Hierarchy Process module in AHP_HeGES is to guide experts to identify the most important heuristics and sub-heuristic in evaluating usability of educational computer games. Figure 2 shows the heuristics and sub-heuristics for PHEG. The goal is to rank the heuristics (known as dimensions) and sub-heuristics (known as criteria).

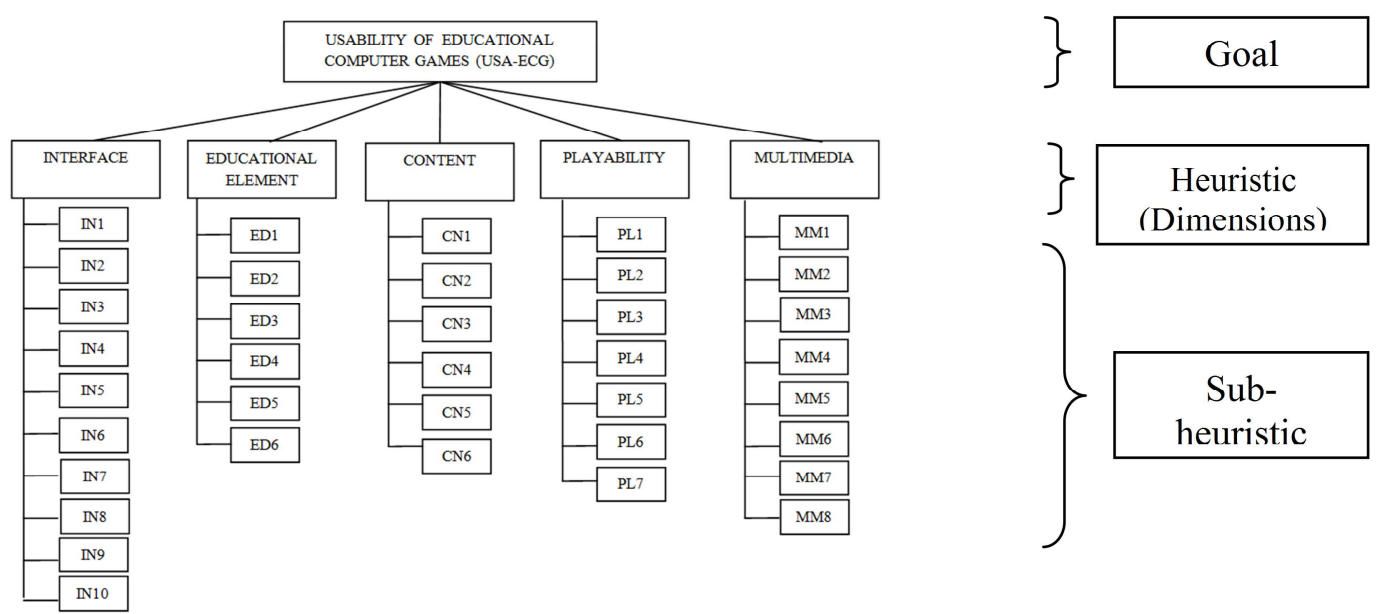

Figure 2. The hierarchy structure of PHEG

\subsection{Guided Analytic Hierarchy Process}

Guide Analytic Hierarchy Process (GAHP) is adopted from (Ahmad, 2007), GAHP Model. This model is developed to help the users to perform AHP in a very simple and guided situation. This follows the second principles of AHP that users need to be guided on how to perform AHP. The 
design of decision matrix for the criteria involves columns and rows, this may lead users to interpret it differently. In order to perform a sequence of pair-wise comparisons for the design matrix, how to read the same level hierarchy of the criteria need to be provided. In order to perform GAHP analysis, the system has to be designed in such a way that both horizontal and vertical criteria in a decision matrix need to be arranged in descending order of importance (Ahmad, 2007).

\subsection{Research Procedure}

The main objective is to proritize the most important heuristic and sub-heuristic that can be used in evaluating usability of ECG. The respondents, who are comprised of 15 experts from various field were contacted through email to perform AHP through AHP_HeGES. Twenty five experts were contacted, and 15 replied and agreed to paticipate in the process. Three experts from each field were agreed to participate in the study to perform AHP in order to determine the importance of heuristics. The respondent are in the age groups 35-56 years and consist of 6 male and 9 female.

Respondent need to key in their demographic data and continue to perform AHP on the next page. Each of the respondent need to perform AHP for the 5 heuristics and continue with the specific heuristic based on their expertise. For example, HCI expert, need to perform AHP for 5 heuristic (Interface, Educational elements, content, playability and multimedia) and continue with sub-heuristic for Interface (IN01 unil IN10). Figure 4 shows the print screen on how to perform AHP process. Respondent need to select the GAHP, based on the instruction given. Submit button lead respondent to view details of the calculation involves in AHP method.

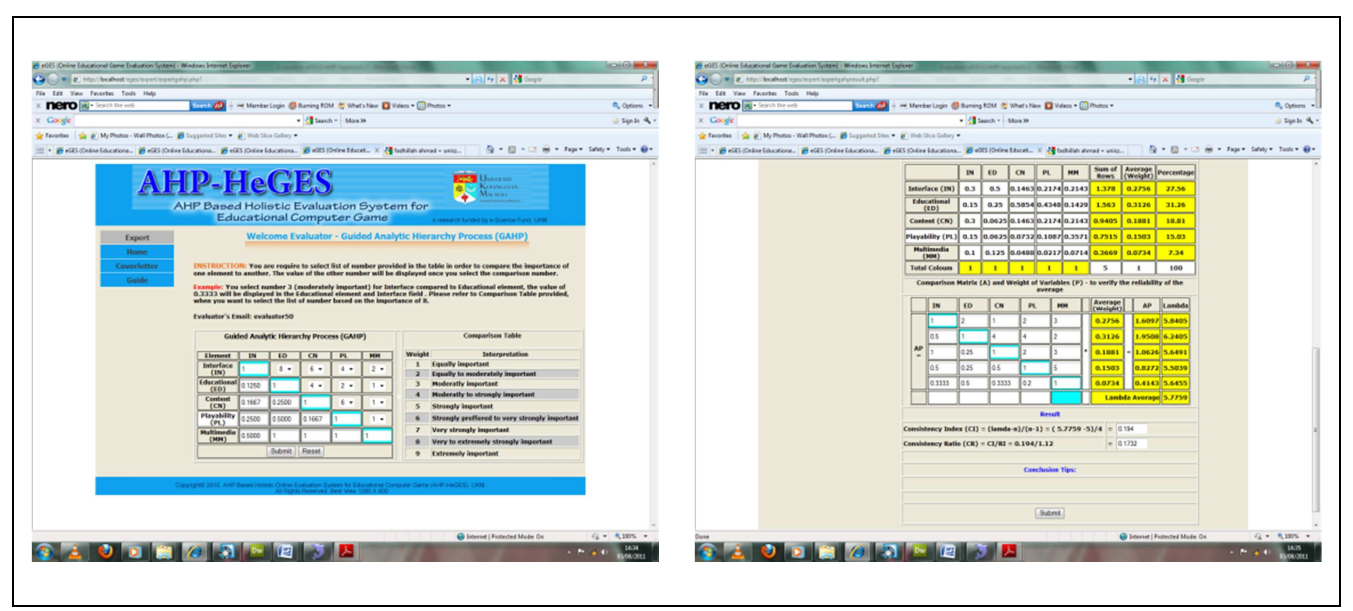

Figure 3. Print Screen of AHP process

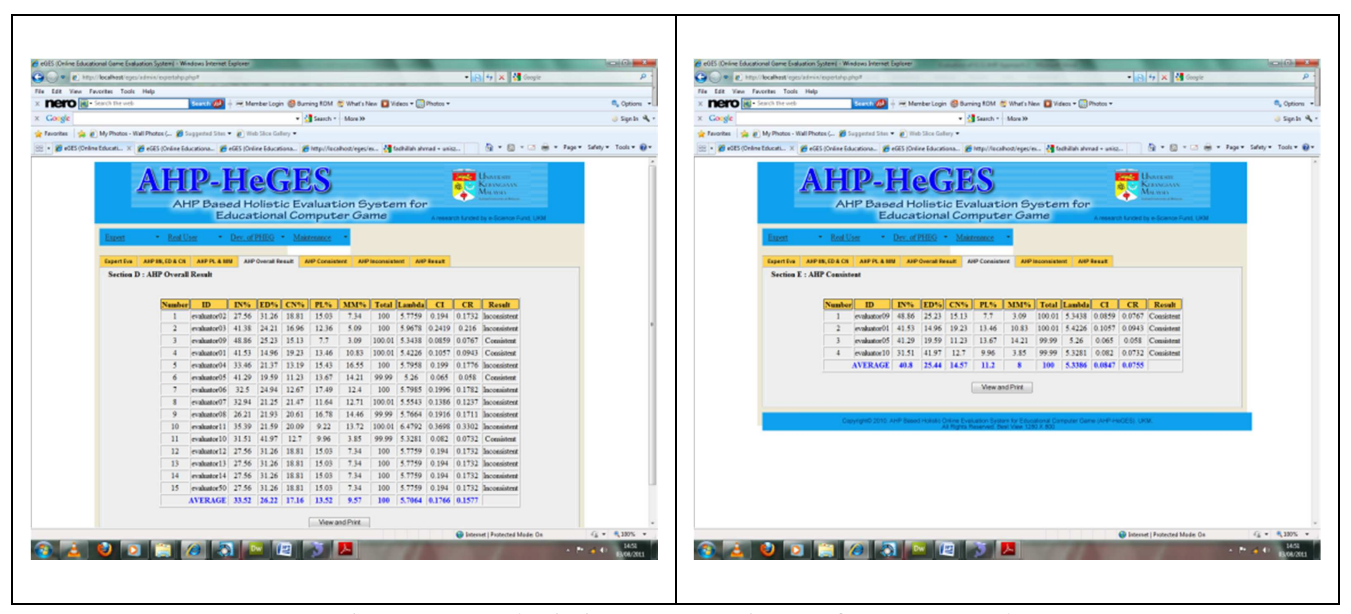

Figure 4. Administrator's view of AHP result 
The result of the AHP method can be viewed by administrator of the system as shown in Figure 5 . Result were divided into overall result (before adjustment), consistent (after adjustment) and inconsistent category. Figure 5 shows result of the AHP method, performed by 15 experts. AHP_HeGES provide report for Analytic Hierarchy Process module, which is easier for the administrator to view the data.

Table 3 shows the overall result (before adjustment), consistent result (after adjustment) and rank of the heuristic. Results of the AHP are based on the average of 15 evaluators involved. Both of the results shows that Interface $(40.8 \%)$ is selected to be the most important heuristic in evaluating Usa_ECG. The second important heuristic is educational element $(25.44 \%)$ followed by content (14.57\%), playability (11.2\%) and multimedia (8\%). There are slightly different percentage value for overall result and consistent ratio group. But overall, the ranking of the important heuristic is the same.

Table 3. Weights and rank of heuristic in PHEG

\begin{tabular}{|c|c|c|c|c|c|c|}
\hline \multirow[b]{2}{*}{ Heuristic } & \multicolumn{2}{|c|}{ Before adjustment } & \multirow[b]{2}{*}{ Rank } & \multicolumn{2}{|c|}{ Before adjustment } & \multirow[b]{2}{*}{ Rank } \\
\hline & $\begin{array}{c}\text { Weight } \\
(\%)\end{array}$ & $\begin{array}{c}\text { Consistency } \\
\text { Ratio (CR) }\end{array}$ & & $\begin{array}{c}\text { Weight } \\
(\%)\end{array}$ & $\begin{array}{c}\text { Consistency } \\
\text { Ratio (CR) }\end{array}$ & \\
\hline Interface (IN) & 33.5 & \multirow{6}{*}{0.1577} & 1 & 40.8 & \multirow{6}{*}{0.0755} & 1 \\
\hline Educational Element (ED) & 26.22 & & 2 & 25.44 & & 2 \\
\hline Content $(\mathrm{CN})$ & 17.16 & & 3 & 14.57 & & 3 \\
\hline Playability (PL) & 13.52 & & 4 & 11.2 & & 4 \\
\hline Multimedia (MM) & 9.57 & & 5 & 8 & & 5 \\
\hline Total & 100 & & & 100 & & \\
\hline
\end{tabular}

Table 4 shows the overall result (before adjustment), consistent result (after adjustment) and rank of the Interface heuristic. AHP results for Interface heuristics were performed by three interface experts. Result shows that all of the consistency ratio are not consistent. Ranking of the 10 sub-heuristic can be identified but it cannot be confirmed due to the inconsistency result of CR.

Table 4. Weights and rank of sub-heuristic for Interface heuristic

\begin{tabular}{|l|l|l|l|}
\hline \multirow{2}{*}{ Sub-Heuristic } & \multicolumn{2}{|c|}{ Before adjustment } & \multirow{2}{*}{ Rank } \\
\cline { 2 - 2 } & $\begin{array}{c}\text { Weight } \\
(\%)\end{array}$ & $\begin{array}{c}\text { Consistency } \\
\text { Ratio (CR) }\end{array}$ & \\
\hline IN01 & 19.59 & & 1 \\
\hline IN02 & 15.51 & & 2 \\
\hline IN03 & 15.26 & \multirow{5}{*}{0.4100} & 3 \\
\hline IN04 & 13.40 & \\
\hline IN05 & 12.34 & 5 \\
\hline IN06 & 7.35 & & 6 \\
\hline IN07 & 5.38 & & 7 \\
\hline IN08 & 4.16 & & 8 \\
\hline IN09 & 3.57 & & 9 \\
\hline IN10 & 2.98 & & 10 \\
\hline Total & 100 & & \\
\hline & & \\
& & & \\
\hline
\end{tabular}

Table 5,6,7 and 8 shows the overall result (before adjustment), consistent result (after adjustment) and rank of the Educational element, content, playability and multimedia heuristic respectively. All of these heuristics were performed by three experts for each heuristic. Difference percentage value and ranking for before adjustment and after adjustment result are shown in Table 5,6,7 and 8. 
Table 5. Weights and rank of heuristic in PHEG

\begin{tabular}{|c|c|c|c|c|c|c|}
\hline \multirow[b]{2}{*}{ Sub-Heuristic } & \multicolumn{2}{|c|}{ Before adjustment } & \multirow[b]{2}{*}{ Rank } & \multicolumn{2}{|c|}{ Before adjustment } & \multirow[b]{2}{*}{ Rank } \\
\hline & $\begin{array}{c}\text { Weight } \\
(\%)\end{array}$ & $\begin{array}{c}\text { Consistency } \\
\text { Ratio (CR) }\end{array}$ & & $\begin{array}{c}\text { Weight } \\
(\%)\end{array}$ & $\begin{array}{c}\text { Consistency } \\
\text { Ratio (CR) }\end{array}$ & \\
\hline ED01 & 24.81 & \multirow{6}{*}{1.454} & 1 & 23.26 & \multirow{6}{*}{0.060} & 1 \\
\hline ED02 & 19.23 & & 2 & 16.45 & & 3 \\
\hline ED03 & 15.26 & & 3 & 10.07 & & 6 \\
\hline ED04 & 13.89 & & 5 & 21.38 & & 2 \\
\hline ED05 & 14.63 & & 4 & 15.47 & & 4 \\
\hline ED06 & 12.20 & & 6 & 13.37 & & 5 \\
\hline Total & 100 & & & 100 & & \\
\hline
\end{tabular}

Table 6. Weights and rank of heuristic in PHEG

\begin{tabular}{|c|c|c|c|c|c|c|}
\hline \multirow[b]{2}{*}{ Sub-Heuristic } & \multicolumn{2}{|c|}{ Before adjustment } & \multirow[b]{2}{*}{ Rank } & \multicolumn{2}{|c|}{ Before adjustment } & \multirow[b]{2}{*}{ Rank } \\
\hline & $\begin{array}{c}\text { Weight } \\
(\%)\end{array}$ & $\begin{array}{l}\text { Consistency } \\
\text { Ratio (CR) }\end{array}$ & & $\begin{array}{c}\text { Weight } \\
(\%)\end{array}$ & $\begin{array}{l}\text { Consistency } \\
\text { Ratio (CR) }\end{array}$ & \\
\hline CN01 & 23.22 & \multirow{6}{*}{0.2648} & 2 & 27.47 & \multirow{6}{*}{0.050} & 1 \\
\hline $\mathrm{CNO2}$ & 24.50 & & 1 & 15.65 & & 4 \\
\hline CN03 & 17.47 & & 3 & 18.46 & & 3 \\
\hline CN04 & 15.34 & & 4 & 23.36 & & 2 \\
\hline CN05 & 10.29 & & 5 & 5.91 & & 6 \\
\hline CN06 & 9.17 & & 6 & 9.15 & & 5 \\
\hline Total & 100 & & & 100 & & \\
\hline
\end{tabular}

Table7. Weights and rank of heuristic in PHEG

\begin{tabular}{|c|c|c|c|c|c|c|}
\hline \multirow[b]{2}{*}{ Sub-Heuristic } & \multicolumn{2}{|c|}{ Before adjustment } & \multirow[b]{2}{*}{ Rank } & \multicolumn{2}{|c|}{ Before adjustment } & \multirow[b]{2}{*}{ Rank } \\
\hline & $\begin{array}{c}\text { Weight } \\
(\%)\end{array}$ & $\begin{array}{c}\text { Consistency } \\
\text { Ratio (CR) }\end{array}$ & & $\begin{array}{c}\text { Weight } \\
(\%)\end{array}$ & $\begin{array}{l}\text { Consistency } \\
\text { Ratio (CR) }\end{array}$ & \\
\hline PL01 & 31.56 & \multirow{7}{*}{0.2564} & 1 & 25.29 & \multirow{7}{*}{0.0562} & 1 \\
\hline PL02 & 16.10 & & 3 & 20.58 & & 2 \\
\hline PL03 & 16.76 & & 2 & 11.83 & & 5 \\
\hline PL04 & 9.56 & & 5 & 15.52 & & 3 \\
\hline PL05 & 12.44 & & 4 & 13.09 & & 4 \\
\hline PL06 & 6.49 & & 7 & 6.78 & & 7 \\
\hline PL07 & 7.09 & & 6 & 6.91 & & 6 \\
\hline Total & 100 & & & 100 & & \\
\hline
\end{tabular}

Table 8. Weights and rank of heuristic in PHEG

\begin{tabular}{|c|c|c|c|c|c|c|}
\hline \multirow[b]{2}{*}{ Sub-Heuristic } & \multicolumn{2}{|c|}{ Before adjustment } & \multirow[b]{2}{*}{ Rank } & \multicolumn{2}{|c|}{ Before adjustment } & \multirow[b]{2}{*}{ Rank } \\
\hline & $\begin{array}{c}\text { Weight } \\
(\%)\end{array}$ & $\begin{array}{c}\text { Consistency } \\
\text { Ratio (CR) }\end{array}$ & & $\begin{array}{c}\text { Weight } \\
(\%)\end{array}$ & $\begin{array}{l}\text { Consistency } \\
\text { Ratio (CR) }\end{array}$ & \\
\hline MM01 & 32.75 & & 1 & 25.62 & & 1 \\
\hline MM02 & 22.02 & & 2 & 15.55 & & 2 \\
\hline MM03 & 13.82 & & 3 & 12.84 & & 4 \\
\hline MM04 & 11.06 & & 4 & 14.3 & & 3 \\
\hline
\end{tabular}




\begin{tabular}{|c|c|c|c|c|c|c|}
\hline MM05 & 9.03 & \multirow[t]{4}{*}{0.4292} & 5 & 9.24 & \multirow[t]{4}{*}{0.0723} & 6 \\
\hline MM06 & 5.65 & & 6 & 9.65 & & 5 \\
\hline MM07 & 3.32 & & 7 & 6.24 & & 8 \\
\hline MM08 & 2.35 & & 8 & 6.56 & & 7 \\
\hline Total & 100 & & & 100 & & \\
\hline
\end{tabular}

\section{Discussion}

PHEG evaluation technique that consists of heuristics and sub-heuristics were rank using Analytic Hierarchy Process method by different experts based on their specialization. AHP for PHEG was performed by 15 experts from various fields of studies (interface, educational technologist, Subject matter expert, game developer and multimedia experts). AHP result shows that for overall PHEG ranking result, Interface heuristic $(40.8 \%)$ is selected to be the most important heuristic in evaluating usability of ECG. The second important heuristic is educational element $(25.44 \%)$ followed by Content (14.57\%) and Playability (11.2\%). Multimedia (8\%) heuristic was rank the least important.

AHP for each of the heuristic were performed by 3 experts respectively. Interface heuristic that consist of 10 sub-heuristic shows that all of the results are not consistent (CR>0.1). Eventhought ranking for the sub-heuristic can be identified, but it can be argued because the value of CR is not consistent. Educational elements, content, playability and multimedia heuristics result shows the difference in term of percentage values and the ranking. Sub-heuristic ranking for four hueristics are based on the percentage value of after adjustment with the value of CR is less than 0.1 (indicate that the ranking process was consistence).

This represent that in any application development, interface plays an important part in order to attract user to use the system. Evaluation process that normally being done during the development or formative evaluation, serious consideration need to be taken into account so that interface of the applications is suitable and attractive enough. The importance of other heuristics plays their own roles in evaluating educational computer games. The most important things are developers; educational technologist and subject matter experts know how to merge the element of fun and education in developing educational computer games.

\section{Conclusion}

Heuristic based evaluation technique to evaluate educational computer games was developed known as PHEG. PHEG consists of five heuristics and the importance of each heuristic in unknown. In order to determine the ranking of the heuristics and sub-heuristics, AHP technique is used and 15 experts were involved. Result of AHP is used to rank heuristics and sub-heuristics of PHEG. The ability of AHP method to identify consistency of the result given by evaluators help to differentiate either the result is consistent or not. Result shows that interface is the most important heuristic in evaluating the usability of educational computer games. An extension work on this research can be conducted for future enhancement. One possible direction for future research is the evaluation result (usability problem) using PHEG technique to evaluate ECG. The usability problems found in the evaluation result can be rated using Analytical Hierarchy Process.

\section{REFERENCES}


Ahmad, F.; Saman, M.Y.M.; Mohamad Noor, N.M.; Othman, A.;. (2007, 15-18 Dec. 2007). "DSS for Tendering Process: Integrating Statistical Single-Criteria Model with MCDM Models," Paper presented at the IEEE International Symposium on Signal Processing and Information Technology.

Albion, P. (1999). Heuristic evaluation of educational multimedia: From theory to practice. Paper presented at the 16th Annual Conference of the Australasian Society for Computers in Learning in Tertiary Education, Brisbane.

Barendregt, W., Bekker, M. M., Bouwhuis, D. G., \& Baauw, E. (2006). Identifying usability and fun problems in a computer game during first use and after some practice. International Journal of Human-Computer Studies, 64(9), 830-846.

Benson, L., Elliott, D., Grant, M., Holschuh, D., Kim, B., Kim, H., Lauber, E., Loh, S. \& Reeves, T.C. (2002). Usability and Instructional Design Heuristics for E-Learning Evaluation. Paper presented at the World Conference on Educational Multimedia, Hypermedia and Telecommunications, Chesapeake, VA.

Clanton, C. (1998). An interpreted demonstration of computer game design. Paper presented at the CHI 98 summary: Human Factors in Computing Systems. Chi 98.

Dempsey, J. V., Lucassen, B. A., Haynes, L. L., \& Casey, M. S. (1997). An exploratory study of forty computer games (COE Technical Report No 97-2). Mobile, Al. University of South Alabama.

Desurvire, H., Caplan, M., Toth, J.A. (2004). Using heuristics to evaluate the playability of games. Paper presented at the Computer Human Interaction (CHI) 2004, Vienna, Austria.

Federoff, M. A. (2002). Heuristics And Usability Guidelines For The Creation And Evaluation Of Fun In Video Games. Indiana University.

Hannu, Korhonen, \& Elina, M. I. Koivisto. (2006). Playability heuristics for mobile games. Paper presented at the Proceedings of the 8th conference on Human-computer interaction with mobile devices and services, Helsinki, Finland.

Ke, F. (2008). Alternative goal structures for computer game-based learning. International Journal of ComputerSupported Collaborative Learning, 3(4), 429.

Malone, T.W. (1980). What makes things fun to learn? Heuristics for designing instructional computer games. Paper presented at the In: Proceedings of the 3rd ACM SIGSMALL Symposium and the First SIGPC Symposium on Small Systems.

Mohamed, H., \& Jaafar, A. (2010). Challenges in the evaluation of educational computer games. Paper presented at the Information Technology (ITSim), 2010 International Symposium in.

Nielsen, J. (1994). Heuristic evaluation. New York: John Wiley \& Sons.

Nielsen, Jacob, \& Molich, R. (1994). Heuristics Evaluation of User Interfaces. Paper presented at the In Proceedings of Human Computer Interaction.

Nokelainen, P. (2006). An empirical assessment of pedagogical usability criteria for digital learning material with elementary school students. Educational Technology \& Society, 9(2), 178-197.

Papastergiou, Marina. (2009). Digital Game-Based Learning in high school Computer Science education: Impact on educational effectiveness and student motivation. Computers \& Education, 52(1), 1-12.

Pinelle, David, \& Wong, Nelson. (2008). Heuristic evaluation for games: usability principles for video game design. Paper presented at the Proceedings of ACM CHI 2008 Conference on Human Factors in Computing Systems.

Quinn, CN. (1996). Pragmatic evaluation: lessons from usability. Paper presented at the 13th Annual Conference of the Australasian Society for Computers in Learning in Tertiary Education, Australasian Society for Computers in Learning in Tertiary Education. 
Saaty, TL. (1990). How to make a decision: the analytic hierarchy process. European Journal of Operational Research, 48(1), 9-26.

Saaty, TL. (1994). Fundamentals of decision making. Pittsburgh: RWS Publications.

Shee, Daniel Y., \& Wang, Yi-Shun. (2008). Multi-criteria evaluation of the web-based e-learning system: A methodology based on learner satisfaction and its applications. Computers \& Education, 50(3), 894-905.

Song, Seungkeun, \& Lee, Joohyeon. (2008). Retraction notice to "Key factors of heuristic evaluation for game design: Towards massively multi-player online role-playing game" [Int. J. Human-Computer Studies 65 (2007) 709-723]. International Journal of Human-Computer Studies, 20(5), 391.

Ssemugabi, Samuel, \& Villiers, Ruth de. (2007). A comparative study of two usability evaluation methods using a web-based e-learning application. Paper presented at the Proceedings of the 2007 annual research conference of the South African institute of computer scientists and information technologists on IT research in developing countries, Port Elizabeth, South Africa.

Taylor, Mark John, Pountney, David C., \& Baskett, M. (2008). Using animation to support the teaching of computer game development techniques. Computers \& Education, 50(4), 1258-1268. 